\title{
Aryl thiosemicarbazones: In vitro and immunomodulatory activities against L. amazonensis
}

\author{
Aline Caroline da Silva ${ }^{a}$ *, Thiago André Ramos dos Santos a \\ Isis Viviane Bezerra da Silva a, Marcos Victor Gregório de Oliveira c, \\ Diogo Rodrigo Magalhães Moreira ${ }^{b}$, Ana Cristina Lima Leite ${ }^{c}$, Valéria Rêgo Alves Pereira ${ }^{a}$ \\ a Departamento de Imunologia, Centro de Pesquisas Aggeu Magalhães, Recife, Pernambuco, Brazil \\ ${ }^{\mathrm{b}}$ Laboratório de Engenharia Tecidual e Imunofarmacologia, Centro de Pesquisas Gonçalo Moniz, Salvador, Bahia, Brazil \\ c Departamento de Ciências Farmacêuticas, Universidade Federal de Pernambuco, Recife, Pernambuco, Brazil
}

\section{H I G H L I G H T S}

- Aryl thiosemicarbazone derivatives have low toxicity to host cells.

- Aryl thiosemicarbazone demonstrated direct activity on L. amazonensis in vitro.

- Macrophage Modulation by cytokines TNF, IL-10, IL-12 and nitric oxide was detected.

\section{A R T I C L E I N F O}

\section{Article history:}

Received 19 October 2016

Received in revised form

27 February 2017

Accepted 18 April 2017

Available online 19 April 2017

\section{Keywords:}

Cutaneous leishmaniasis

Chemotherapy

Synthetic compound

Thiosemicarbazone

\section{G R A P H I C A L A B S T R A C T}

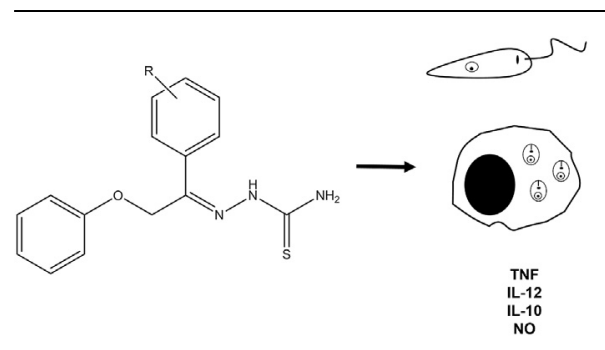

\begin{abstract}
A B S T R A C T
Leishmaniasis is an infection caused by different species of Leishmania genus. Currently, there is no vaccine available for Leishmania infections in humans and conventional treatments are limited due to side effects. Therefore, the development of new antileishmanial drugs is an urgent need. In present study, we evaluated the cytotoxicity in host cells, leishmanicidal activity and immunomodulatory potential of seven aryl thiosemicarbazones. Host cell cytotoxicity was determined in peritoneal macrophages of $\mathrm{BALB} / \mathrm{c}$ mouse, antiparasitic activity was determined against promastigotes and amastigotes of WHOM/ 00LTB 0016 strain of L. amazonensis. Nitric oxide (NO) production, interleukin (IL)-12, IL-10 and TNFalpha secretion were measured in the supernatant of uninfected and infected macrophage cultures. It was observed that aryl thiosemicarbazones presented in vitro antiparasitic activity against both extracellular and intracellular forms of L. amazonensis. However, unlike Amphotericin B, these compounds displayed low cytotoxicity towards host cells. In addition to observed antiparasitic activity, compounds exhibited modulatory properties in the secretion of cytokines and nitrite content from uninfected stimulated and L. amazonensis-infected macrophages. In conclusion, we demonstrated the in vitro antiparasitic activity against $L$. amazonensis for aryl thiosemicarbazones, which is possible achieved by Th1 cytokine profile modulation. These findings are potential useful for drug development against cutaneous leishmaniasis.
\end{abstract}

() 2017 Elsevier Inc. All rights reserved.

\footnotetext{
* Corresponding author.

E-mail address: aline.caroline.bm@gmail.com (A.C. da Silva).
}

\section{Introduction}

Leishmaniasis is a chronic disease caused by kinetoplastid protozoa belonging to Leishmania genus, which are transmitted from 
animals to humans by sandflies. The disease has diverse clinical manifestations depending on both infecting species of Leishmania and host immune response (Gurung and Kanneganti, 2015). According to World Health Organization (WHO), leishmaniasis is among the six most important tropical diseases. It is estimated that there are about 1.3 million new cases every year and that 310 million people under infection risk (WHO, 2015).

Among measures taken to disease control, the main ones are: vector and reservoir animals control, early diagnosis and treatment for human cases. On the past seventy years, pentavalent antimonials (SbV) have been the first-line drug in treatment for all types of leishmaniasis. Sodium stibogluconate $\left(\right.$ Pentostam $^{\mathbb{R}}$ ) and meglumine antimoniate (Glucantime ${ }^{\mathbb{R}}$ ) are principally used. In view of their higher toxicity, AmB and Pentamidine are second-line drugs, which are recommended in cases of contraindication, intolerance or resistance to antimonials (de Vries et al., 2015).

Limitations of current treatment includes: hospital care, due to side effects, that make treatment expensive and drug nonresponsive patients occurrence owing to either drug-resistant parasite strains or immunosuppression in HIV co-infection cases (Boer et al., 2011; Croft et al., 2006; Leprohon et al., 2015). Therefore, research to find alternatives more effective, with fewer side effects and low cost associated are extremely necessary and recommended by WHO (WHO, 2015, 2010).

A number of compounds obtained through synthesis have emerged in the last decades as antiparasitic agents, among them thiosemicarbazones are some of the most promising in terms of efficacy and action spectrum. Thiosemicarbazones stand out for their broad pharmacological profile, whose properties have been widely studied due to possible of handling their radicals, coordinating their mechanism of action. Among promising biological activities of these compounds can be highlighted: anticonvulsant, antimicrobial, antiviral, antiparasitic and antitumor activities (Beraldo, 2004; Heng et al., 2015; Lessa et al., 2011a, 2011b; Santiago et al., 2014).

Activity of compounds derived from thiosemicarbazone structure on Trypanosoma cruzi is associated with cruzain inhibition, a cysteine protease found abundantly in trypanosomatid, which was named after it was initially identified in T. cruzi (Zaldini et al., 2010). On Leishmania sp., cysteine proteases occurring in large amounts in megasome, organelle particularly abundant in amastigote form. These enzymes, likewise cruzain, play important roles in Leishmania as virulence, maintaining parasite viability and morphology, host mononuclear phagocyte invasion and modulating its immune response, thus constituting attractive chemotherapeutic target in leishmaniasis treatment (Mottram et al., 2004; Schad et al., 2016; Schroder et al., 2013).

The lack of compounds that act with more selectivity on leishmaniasis parasite, without causing much damage to man, reinforces the need of novel therapeutic agents. This study evaluated the leishmanicidal activity of seven synthetic products derived from thiosemicarbazone structure. It was determined toxicity of these compounds on macrophages and activity on promastigotes and amastigotes of $L$. amazonensis, in addition to assessing their potential immunomodulatory effect on macrophages. Therefore, the aims of this study was the investigation of in vitro activity against $L$. amazonensis and immunomodulatory effects for a class of aryl thiosemicarbazones.

\section{Materials and methods}

\subsection{Synthesis of compounds}

Aryl thiosemicarbazone compounds (Fig. 1) were synthesized at Laboratory of Planning and Medicinal Chemistry in Federal

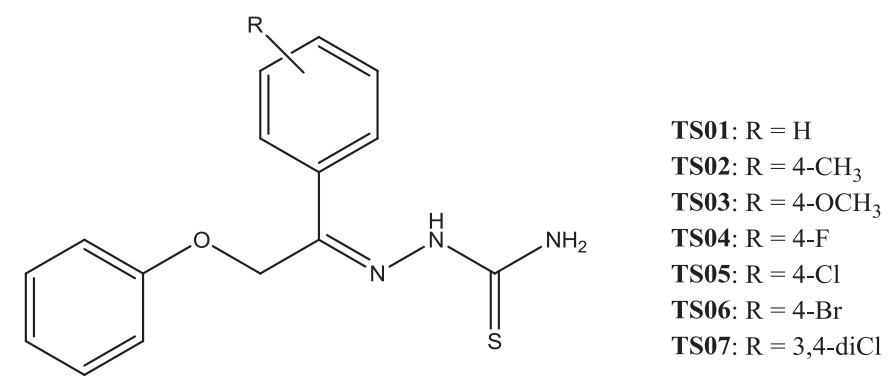

Fig. 1. Structures of aryl thiosemicarbazones studied here.

University of Pernambuco (UFPE), Brazil as previously described (Magalhaes Moreira et al., 2014). All reagents used for synthesis were purchased from commercial sources (Sigma-Aldrich, Acros Organics, Vetec, or Fluka). Progress of the reactions was followed by thin-layer chromatography (silica gel 60 F254 in aluminum foil). IR was determined in $\mathrm{KBr}$ pellets. For NMR, it was used a Bruker AMX$300 \mathrm{MHz}\left(300 \mathrm{MHz}\right.$ for ${ }^{1} \mathrm{H}$ and $75.5 \mathrm{MHz}$ for ${ }^{13} \mathrm{C}$ ) instrument. DMSO- $d_{6}$ was purchased from CIL. Mass spectrometry experiments were performed on a Q-TOF spectrometer LC-IT-TOF (Shimadzu). After chemical characterization, compounds were solubilized in DMSO (Sigma) and dissolved in culture medium (RPMI (Cultilab, Brazil) or Schneider's(Sigma, USA)) before use in experiments.

\subsection{Animals, peritoneal macrophages and parasites}

Male BALB/c mice, at 6-8 weeks of age and between 20 and $25 \mathrm{~g}$ were provide by animal facilities of the Oswaldo Cruz Foundation (Rio de Janeiro, Brazil) and maintained at animal facilities of Aggeu Magalhães Research Center of Oswaldo Cruz Foundation in Recife, Brazil. Animals were maintained under standard conditions on a constant $12 \mathrm{~h}$ light/dark cycle with controlled temperature $\left(22 \pm 2{ }^{\circ} \mathrm{C}\right)$. Food and water were given ad libitum. The procedures performed on animals in this study have approval by the Ethics Committee for Animal Use (CEUA/FIOCRUZ 26/2011).

For peritoneal macrophages obtaining, animals were euthanized and peritoneal cavity was washed with complete RPMI 1640 medium $(100 \mu \mathrm{g} / \mathrm{ml}$ streptomycin (Cultilab, Brazil), $100 \mathrm{U} / \mathrm{ml}$ penicillin (Cultilab, Brazil) and 10\% de fetal calf serum (FCS; Cultilab, Brazil)). Cells were counted and concentration was adjusted for each experiment.

L. amazonensis promastigotes (WHOM/00 LTB 0016) were grown at $26{ }^{\circ} \mathrm{C}$ in Schneider's medium with $10 \%$ FCS. Intracellular amastigotes forms were obtained inoculating infective promastigotes in murine macrophages cultures at 8:1 parasites:macrophage ratio.

\subsection{Macrophages cytotoxicity}

Peritoneal macrophages were used to assess cell cytotoxicity by MTT (3-(4,5-Dimethyl-2-thiazolyl)-2,5-diphenyl-2H-tetrazolium bromide, Sigma, USA) assay (Leite et al., 2013). Cells $\left(1 \times 10^{5}\right.$ cells/ well) were plated in 96 well plates and incubated for $24 \mathrm{~h}\left(37^{\circ} \mathrm{C}, 5 \%\right.$ $\mathrm{CO} 2)$. Then, compounds were added, in six concentrations $(1,5,10$, 25,50 and $100 \mu \mathrm{g} / \mathrm{mL}$ ) and incubated for $48 \mathrm{~h}$. Untreated (DMSO) and AmB were employed as controls. After incubation with compounds, MTT at $5 \mathrm{mg} / \mathrm{mL}$ in PBS, was added. Three hours after, cell culture medium was aspirated and $100 \mu \mathrm{L}$ of DMSO was added, solubilizing formazan crystals. Optical density was measured at 540 nm (Thermo Scientific Multiskan ${ }^{\circledR}$, USA). Cytotoxic Concentration for $50 \%$ inhibition of viability $\left(\mathrm{CC}_{50}\right)$ was also calculated by regression analysis using GraphPad Prism software. Assays were 
done in triplicate. Selectivity Index (SI) was determined as the ratio of $\mathrm{CC}_{50}$ values (macrophages) and Inhibitory Concentration for $50 \%$ parasites $\left(\mathrm{IC}_{50}\right)$, for each compound.

\subsection{Promastigotes and amastigotes assays}

Promastigotes were used for an initial screening for leishmanicidal activity (de Mello et al., 2014). Cells were diluted $\left(1 \times 10^{6}\right.$ cells $\left./ \mathrm{mL}\right)$ in Schneider's medium with $10 \%$ fetal calf serum. Briefly, cells were incubated in a 96 well plate with compounds in ten different concentrations $(0.19-100 \mu \mathrm{g} / \mathrm{mL})$ for $96 \mathrm{~h}$ at $26{ }^{\circ} \mathrm{C}$. AmB (Sigma, USA) was used as a reference drug and DMSO as negative control. Cells without treatment were used as negative controls. Cell growth was assessed and $\mathrm{IC}_{50} / 96 \mathrm{~h}$ was determined by regression analysis. Assays were conducted in triplicate.

For intracellular amastigotes culture, macrophages were harvested and plated $\left(3 \times 10^{5}\right.$ cell $\left./ \mathrm{mL}\right)$ in a 24 -well plate with a $13 \mathrm{~mm}$ glass cover slip and allowed to adhere for $48 \mathrm{~h}$, at $37{ }^{\circ} \mathrm{C}$ in $5 \% \mathrm{CO}_{2}$ (de Mello et al., 2014). Adhered macrophages were then infected with promastigotes in the stationary growth phase using a ratio 8:1 at $37{ }^{\circ} \mathrm{C}$ for $4 \mathrm{~h}$. Afterward, non-interiorized parasites were removed by washing and infected culture were incubated for $24 \mathrm{~h}$ in complete RPMI 1640 medium (negative control) and treated with three different compounds concentrations $(6.25-25 \mu \mathrm{g} / \mathrm{ml})$. The cover slips were collected and stained using Panótico staining kit (Laborclin, PR, Brazil). Percentage of infected macrophages was determined by counting 100 cells and its intracellular amastigotes, in triplicate. Leishmanial activity was assessed by decrease of infected macrophages and intracellular amastigotes in cultures treated $(\mathrm{T})$ and non treated (NT), described by formula: \% amastigotes $=\mathrm{T} \times \mathrm{NT} / 100$. From the reduction of infected macrophages and intracellular amastigotes, $\mathrm{IC}_{50}$ was determined by regression analysis.

\subsection{Apoptosis and necrosis assessment}

Annexin-FITC/Propidium Iodide labeling was used to characterize cell death modalities induced by incubation with compounds (Soflaei et al., 2012). Promastigotes $\left(4 \times 10^{7}\right.$ cells $\left./ \mathrm{mL}\right)$ were treated with compounds in its respective $\mathrm{IC}_{50}$ values. $\mathrm{AmB}\left(\mathrm{IC}_{50}\right)$ and Saponin (0.5\%) were used as controls. After incubation, parasites were washed with PBS and ressupended in binding buffer (Annexin $\mathrm{V}$ Binding Buffer- BD Pharmingen ${ }^{\mathrm{TM}}$, USA). For labeling, $10 \mu \mathrm{L}$ of propidium iodide $(50 \mu \mathrm{g} / \mathrm{mL}$ ) and $5 \mu \mathrm{L}$ of Annexin-FITC (BD Pharmingen $^{\mathrm{TM}}$, USA) were added for $15 \mathrm{~min}$ at room temperature in dark. Flow cytometry was conducted in FACSCalibur (Becton \& Dickinson, USA) using Cell Quest software. For each compound we acquire 20,000 events. Assays were conducted in duplicates.

\subsection{Collection of culture supernatants for cytokine quantification and nitric oxide production}

Murine peritoneal macrophages obtained as previously mentioned were plated in 24-well plate $\left(4 \times 10^{5}\right.$ cell $\left./ \mathrm{mL}\right)$ at $37^{\circ} \mathrm{C}$, $5 \% \mathrm{CO}_{2}$. Compounds $(25,12.5$ e $6.25 \mu \mathrm{g} / \mathrm{mL})$ or $\mathrm{AmB}(2,1,0.5,0.25$ e $0.125 \mu \mathrm{g} / \mathrm{mL}$ ) were added and incubated for 24 and $48 \mathrm{~h}$. Peritoneal macrophages infected with parasites were submitted at the same conditions (only $24 \mathrm{~h}$ of incubation) and compounds concentrations. After that time, supernatants were harvested for evaluation of nitric oxide (NO) and cytokine production. Assays were conducted in triplicate.

Griess reagent was used for indirect nitric oxide measurement production by macrophage. Culture supernatants described above were plated in 96 well plates. After that, Griess reagent was added and incubated for $10 \mathrm{~min}$ at room temperature. Absorbance was measured at $540 \mathrm{~nm}$ using THERMO SCIENTIFIC Multiskan FC spectrophotometer. Nitrite concentrations $(\mu \mathrm{M})$ were determined using a standard curve. Assays were conducted in triplicate.

Macrophage culture supernatants were also used for measurement of cytokine production. OptEIA Kit (BDBiosciences, USA) was used for dosage of TNF, IL-10 and IL-12 production, according to the manufacturer's suggested protocols.

\subsection{Statistical analysis}

Linear regression and significance analysis were done using GraphPad Prism 5.0 software. For significance analysis was used ANOVA and Dunnett's test, taking into account $p<0.05$.

\section{Results}

\subsection{Effects of thiosemicarbazones on peritoneal macrophages}

Compounds activity on peritoneal macrophages was evaluated by MTT assay. All compounds tested showed a higher cytotoxicity to parasites when compared to murine macrophages, presenting lower $\mathrm{IC}_{50}$ values than $\mathrm{CC}_{50}$ values. Some compounds showed no toxicity to macrophages in any concentration tested (Table 1). $\mathrm{CC}_{50}$ values ranged between 111.8 and $163.1 \mu \mathrm{M}$ for TS05 and TS01, respectively.

\subsection{In vitro activities against L. amazonensis promastigotes and amastigotes}

Our results in vitro with $L$. amazonensis promastigotes demonstrate that all compounds were able to inhibit cellular growth, with $\mathrm{IC}_{50}$ values ranging between 3.5 and $87.5 \mu \mathrm{M}$ (Table 1 ). TS03 was the most activity compound tested on promastigote.

Evaluated compounds showed lower $\mathrm{IC}_{50}$ values in promastigotes than in intracellular amastigotes, thus demonstrating greater effectiveness against the first. Intracellular amastigotes $\mathrm{IC}_{50}$ values ranged from 18.3 to $40.3 \mu \mathrm{M}$. Amastigotes SI ranged from 2.96 to 4.67. TS06 was the most activity against amastigotes $\left(\mathrm{IC}_{50}=18.3 \mu \mathrm{M}\right)$ and TS04 was the most selective compound.

Reference drug used in this work, AmB, presented strong effectiveness against the $L$. amazonensis strain used in trials, with low $\mathrm{IC}_{50}$ values for both parasite forms and high Selectivity Index.

\subsection{In vitro cytokines induction}

\subsubsection{Tumor necrosis factor (TNF)}

TNF production on macrophages was significantly increased

Table 1

Activity of thiosemicarbazones on murine macrophages and Leishmania amazonensis.

\begin{tabular}{llllll}
\hline Compound & $\mathrm{CC}_{50(\mu \mathrm{M})}$ & $\mathrm{IC}_{50} \mathrm{PRO}_{(\mu \mathrm{M})}$ & $\mathrm{IC}_{50} \mathrm{AMA}_{(\mu \mathrm{M})}$ & $\mathrm{SI}_{\mathrm{PRO}}$ & $\mathrm{SI}_{\text {AMA }}$ \\
\hline TS01 & $163.1 \pm 37.6$ & $6.0 \pm 0.02$ & $33.0 \pm 12.8$ & 27.13 & 3.64 \\
TS02 & $>333.2$ & $12.5 \pm 1.4$ & $37.8 \pm 11.2$ & $\mathrm{ND}$ & $\mathrm{ND}$ \\
TS03 & $155.5 \pm 10.8$ & $3.5 \pm 0.33$ & $34.3 \pm 1.23$ & 44.96 & 3.95 \\
TS04 & $154.4 \pm 10.0$ & $87.5 \pm 2.14$ & $25.1 \pm 5.08$ & 1.76 & 4.67 \\
TS05 & $111.8 \pm 12.1$ & $4.9 \pm 0.15$ & $40.3 \pm 0.42$ & 22.94 & 2.96 \\
TS06 & $>274.7$ & $4.8 \pm 0.21$ & $18.3 \pm 4.04$ & $\mathrm{ND}$ & $\mathrm{ND}$ \\
TS07 & $>284$ & $3.6 \pm 0.9$ & $34.8 \pm 0.03$ & ND & ND \\
AmB & $8.1 \pm 2.3$ & $1.1 \pm 0.15$ & $0.23 \pm 0.02$ & 7.5 & 34.09
\end{tabular}

Note: $\mathrm{CC}_{50}$ : Cytotoxic Concentration for $50 \%$ of macrophages $(\mu \mathrm{M})$. $\mathrm{IC}_{50} \mathrm{PRO}$ : Inhibitory Concentration for $50 \%$ of $L$. amazonensis promastigotes $(\mu \mathrm{M})$. IC $C_{50}$ AMA: Inhibitory Concentration for $50 \%$ of $L$. amazonensis amastigotes $(\mu \mathrm{M})$. SI Pro: Selectivity Index $=\mathrm{CC}_{50}$ Macrophages $/ \mathrm{IC}_{50}$ Promastigotes. $\mathrm{SI}_{\mathrm{AMA}}$ : Selectivity Index $=\mathrm{CC}_{50}$ Macrophages/ $/ \mathrm{IC}_{50}$ Amastigotes.

ND: Not determined. No toxicity in any concentration tested. 
under the influence of TS01 $(6.25 \mu \mathrm{g} / \mathrm{mL})$, TS03 $(6.25 \mu \mathrm{g} / \mathrm{mL})$, TS04 $(12.5 \mu \mathrm{g} / \mathrm{mL})$, TS05 $(12.5 \mu \mathrm{g} / \mathrm{mL})$ after $24 \mathrm{~h}$ of treatment (Fig. 2a). No production of TNF was detected after $48 \mathrm{~h}$ treatment in any situation, as expected.

Macrophage infection with $L$. amazonensis, applied to obtain intracellular amastigotes, caused a significant increase of TNF production in comparison to uninfected control. In presence of compounds, there was a greater increase in production of TNF only with TS01, at lowest concentration tested, and significant decrease of this cytokine in cultures treated with TS05, TS06 and TS07 in lower/ or intermediate concentration when compared to infected and untreated control (Fig. 2b).

\subsubsection{Interleukin-12 (IL-12)}

Significant IL-12 production in supernatants of macrophages was detected after $24 \mathrm{~h}$ incubation with TS01 $(6.25 \mu \mathrm{g} / \mathrm{ml})$, TS02 $(25 \mu \mathrm{g} / \mathrm{ml})$ and TS06 (25 and $12.5 \mu \mathrm{g} / \mathrm{ml})$. On the other hand, after $48 \mathrm{~h}$, significant production of this cytokine was detected in cultures stimulated with compounds TS01 (12.5 and $6.25 \mu \mathrm{g} / \mathrm{ml})$, TS04 (6.25 $\mu \mathrm{g} / \mathrm{ml})$, TS06 $(25 \mu \mathrm{g} / \mathrm{ml})$ and TS07 $(6.25 \mu \mathrm{g} / \mathrm{ml})$ (Fig. 3a and b).

L. amazonensis infected macrophages presented a slight increase in IL-12 production, not statistically significant, after $24 \mathrm{~h}$. When this culture was treated, only compounds TS03 $(6.25 \mu \mathrm{g} / \mathrm{ml})$, TS05
$(6.25 \mu \mathrm{g} / \mathrm{ml})$ and TS07 $(6.25 \mu \mathrm{g} / \mathrm{ml})$ stimulated IL-12 production significantly compared to control (Fig. 3c).

\subsubsection{Interleukin-10 (IL-10)}

During a period of $24 \mathrm{~h}$, there was a significant increase in IL-10 production in presence of compounds TS01 (12.5 and $6.25 \mu \mathrm{g} / \mathrm{ml})$ and TS07 (12.5 and $6.25 \mu \mathrm{g} / \mathrm{ml})$. On the other hand, there was a significant reduction in this cytokine production to TS01 $(25 \mu \mathrm{g} / \mathrm{ml})$, TS03 (25 and $12.5 \mu \mathrm{g} / \mathrm{ml}$ ), TS04 (25 and $6.25 \mu \mathrm{g} / \mathrm{ml})$, TS05 (12.5 $\mu \mathrm{g} /$ $\mathrm{ml})$ and TS06 $(12.5 \mu \mathrm{g} / \mathrm{ml})$ (Fig. $4 \mathrm{a})$.

After $48 \mathrm{~h}$, only TS01 $(12.5$ and $6.25 \mu \mathrm{g} / \mathrm{ml})$ and TSO2 $(25 \mu \mathrm{g} / \mathrm{ml})$ significantly increased IL-10 production, whereas TS03 $(6.25 \mu \mathrm{g} / \mathrm{ml})$ and TS06 $(25 \mu \mathrm{g} / \mathrm{ml})$ reduced their production (Fig. 4b).

L. amazonensis infected macrophages showed a slight reduction in IL-10 production but not significantly. By the same way, different concentrations of compounds no presented significant difference in production of this cytokine (Fig. 4c).

\subsection{In vitro nitric oxide production}

Nitric Oxide production was evaluated in vitro in peritoneal macrophages stimulated or not with compounds after two incubation times: $24 \mathrm{~h}$ and $48 \mathrm{~h}$. In both time was identified production
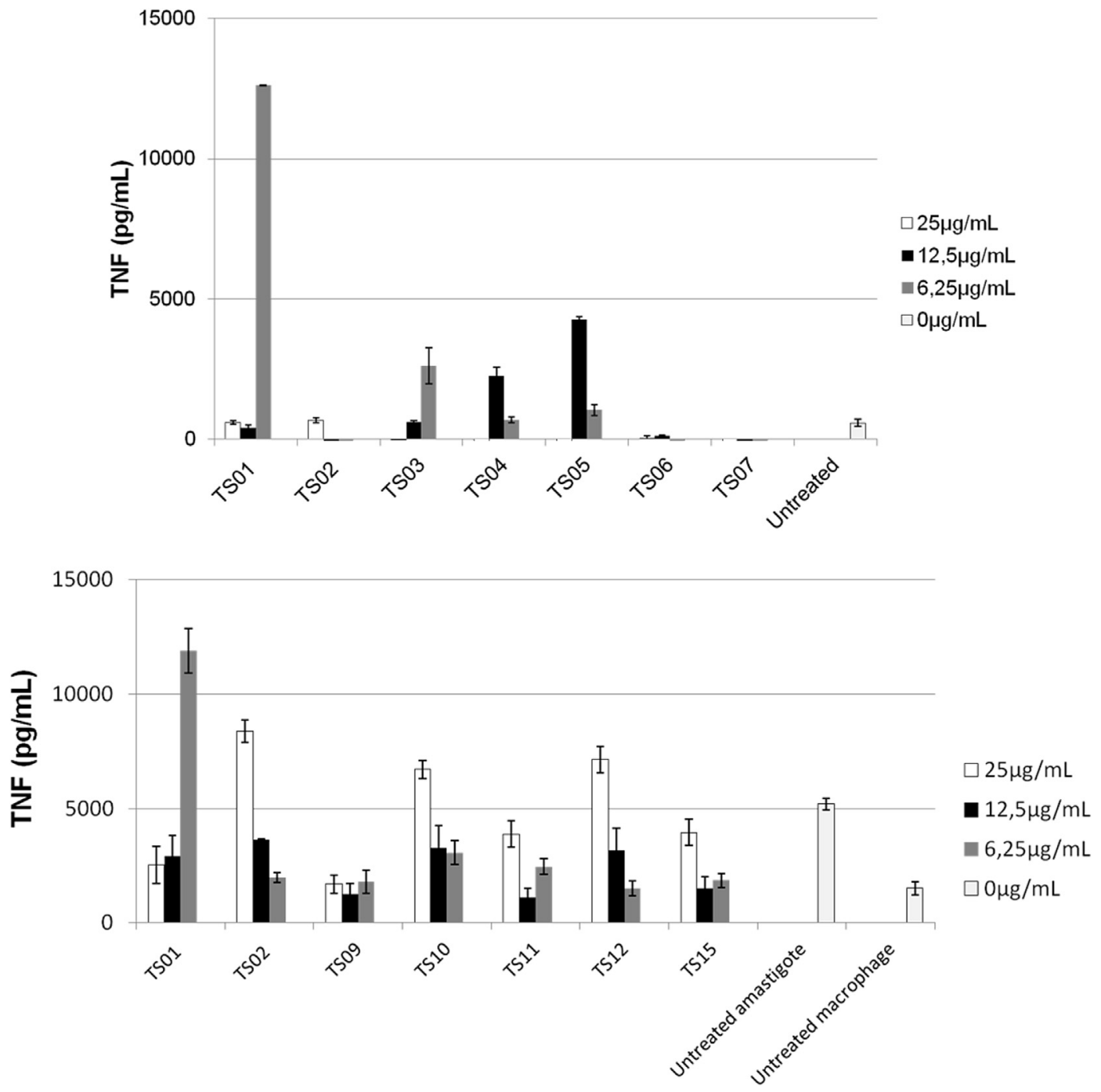

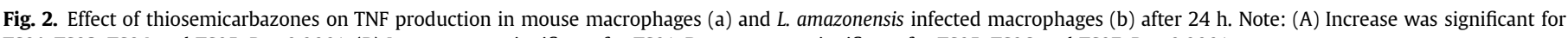
TS01, TS03, TS04 and TS05. P $<0.0001$. (B) Increase was significant for TS01. Decrease was significant for TS05, TS06 and TS07. P $=0.0001$. 
A

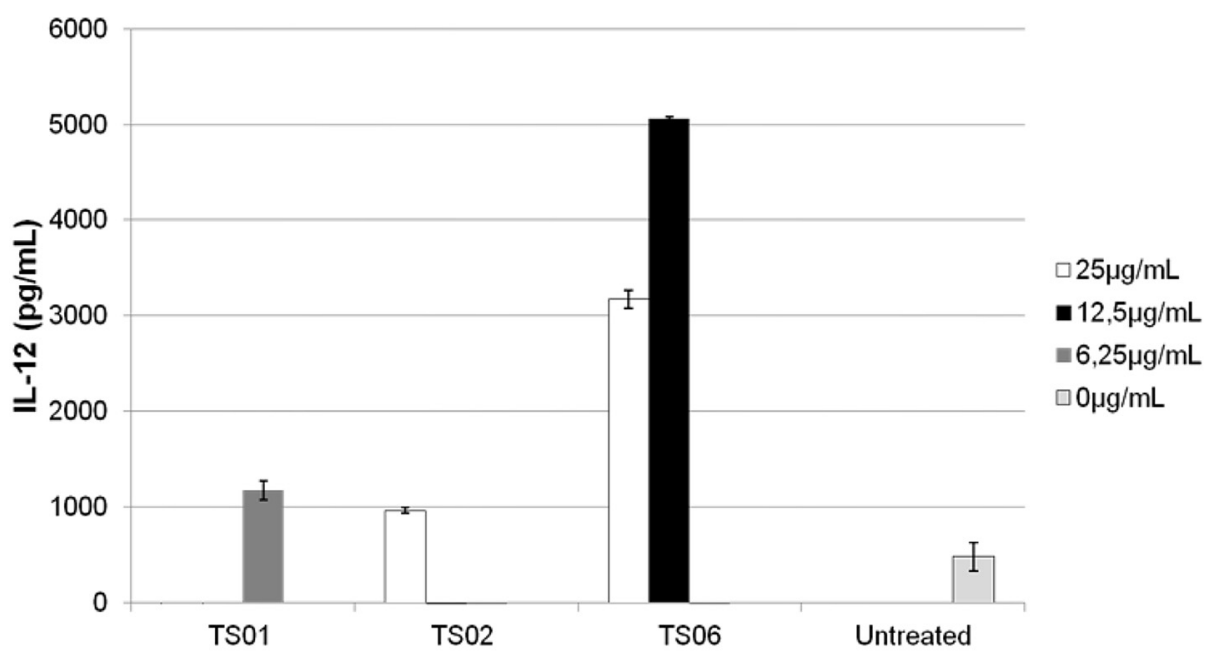

B
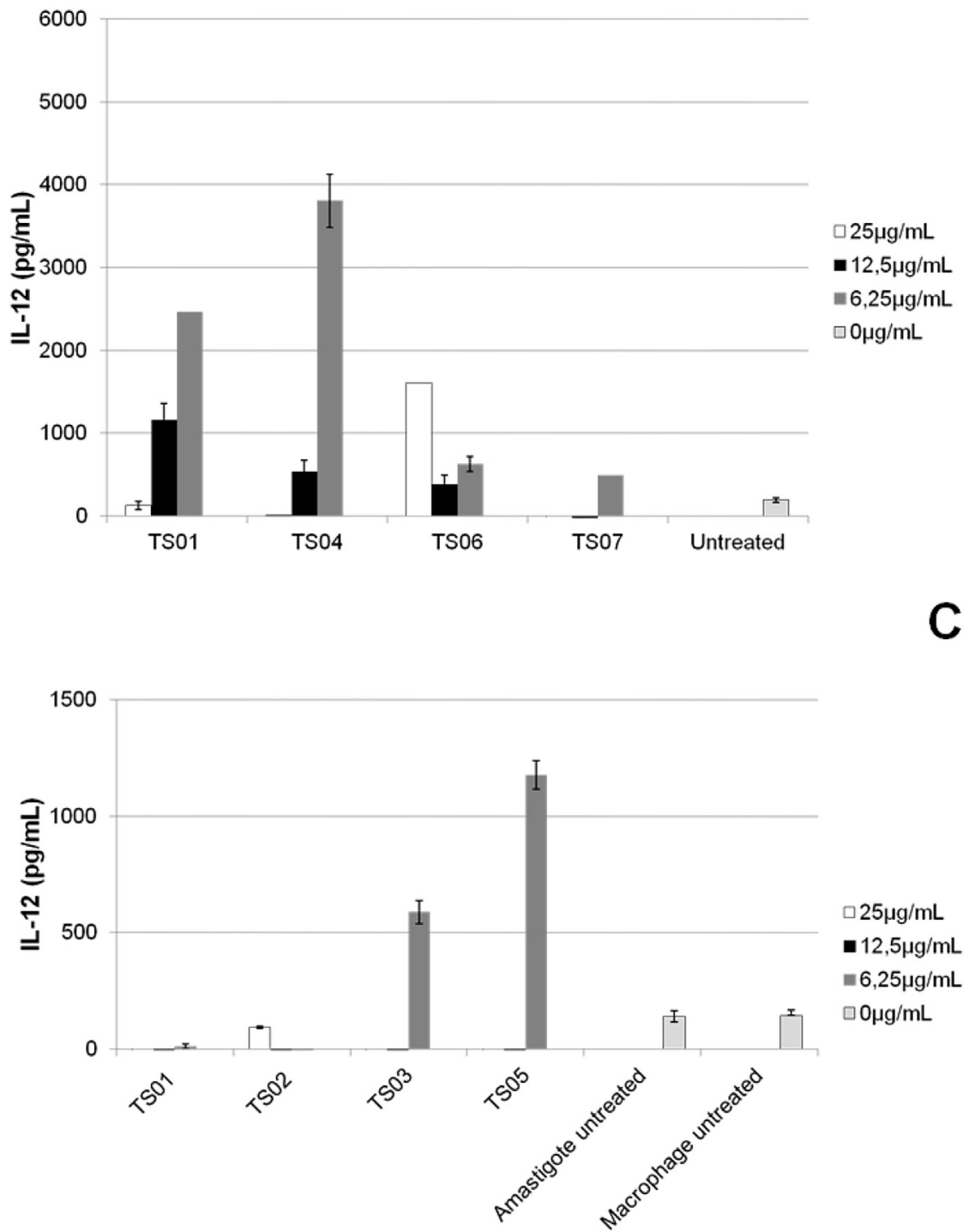

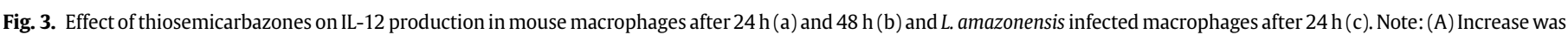
significant for TS01, TS02 and TS06. $\mathrm{P}<0.0001$. (B) Increase was significant for TS01, TS04, TS06 and TS07. P $<0.0001$. (C) Increase was significant for TS03 and TS05. P $<0.0001$. 
A

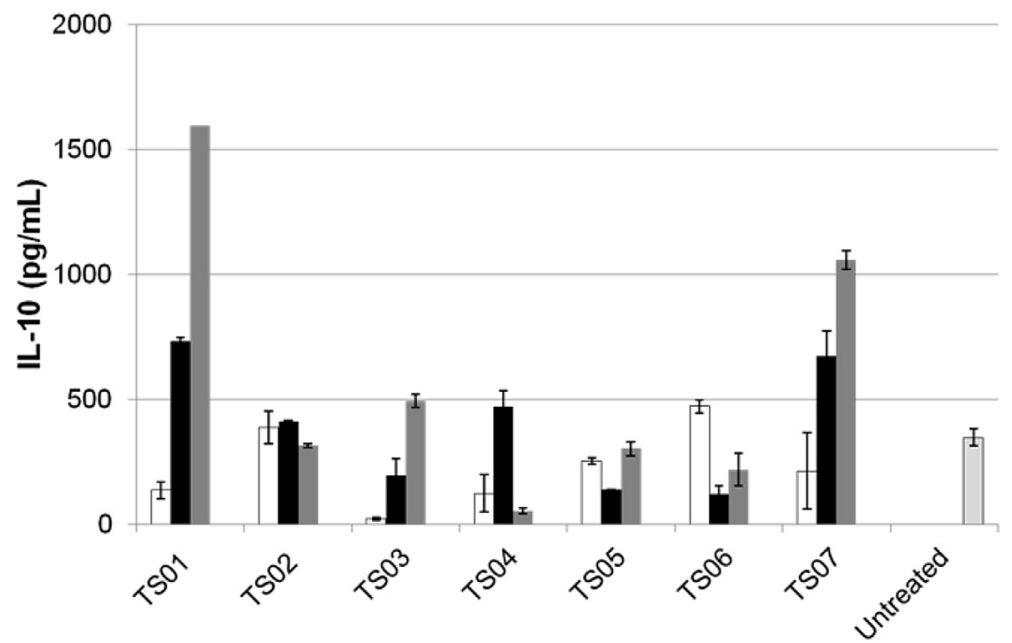

$\square 25 \mu \mathrm{g} / \mathrm{mL}$

- $12,5 \mu \mathrm{g} / \mathrm{mL}$

$=6,25 \mu \mathrm{g} / \mathrm{mL}$

$\square 0 \mu \mathrm{g} / \mathrm{mL}$

B

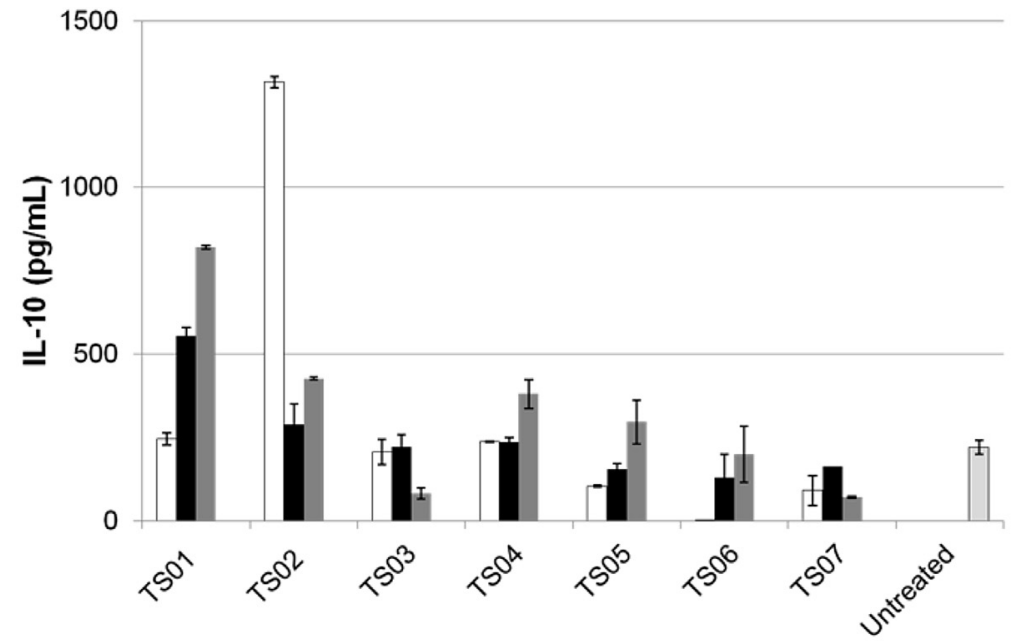

$\square 25 \mu \mathrm{g} / \mathrm{mL}$

- $12,5 \mu \mathrm{g} / \mathrm{mL}$

$=6,25 \mu \mathrm{g} / \mathrm{mL}$

$\square 0 \mu \mathrm{g} / \mathrm{mL}$

C

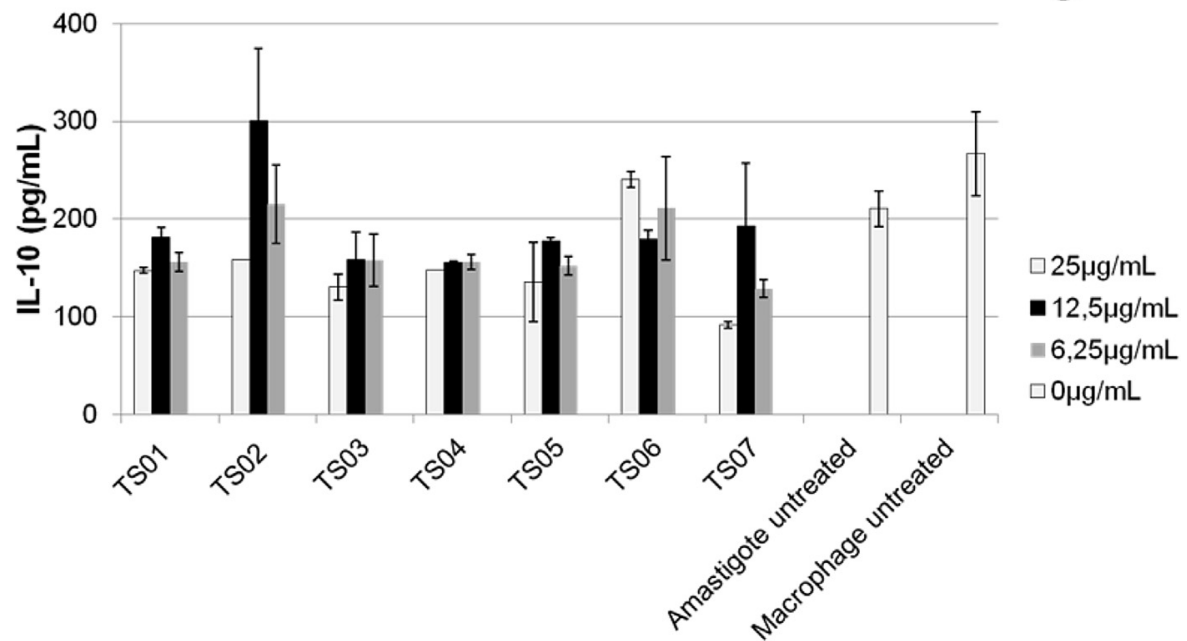

Fig. 4. Effect of thiosemicarbazones on IL-10 production in mouse macrophages after $24 \mathrm{~h}$ (a) and $48 \mathrm{~h}$ (b) and L. amazonensis infected macrophages after $24 \mathrm{~h}$ (c). Note: (A) Increase was significant for TS01 and TS07. P $<0.0001$. (B) Increase was significant for TS01 and TS02. Decrease was significant for TS03 and TS06. P $=0.0002$. (C) No statistically significant difference. $\mathrm{P}=0.2306$ 
Table 2

NO- production in murine macrophages.

\begin{tabular}{|c|c|c|}
\hline \multirow[t]{2}{*}{ Treatment } & \multicolumn{2}{|l|}{$\mathrm{NO}_{2}^{-}(\mu \mathrm{M})$} \\
\hline & $24 \mathrm{~h}$ & $48 \mathrm{~h}$ \\
\hline $\begin{array}{l}\text { Untreated Control } \\
\text { TS01 }(\mu \mathrm{g} / \mathrm{mL})\end{array}$ & $8.8 \pm 0.23$ & $9.26 \pm 0.01$ \\
\hline 25 & $10.7 \pm 0.02 *$ & $7.7 \pm 0.05^{*}$ \\
\hline 12.5 & $10.2 \pm 0.07$ * & $8.6 \pm 0.03^{*}$ \\
\hline 6.25 & $10.6 \pm 0.35$ * & $8.6 \pm 0.02$ \\
\hline \multicolumn{3}{|l|}{ TS02 $(\mu \mathrm{g} / \mathrm{mL})$} \\
\hline 25 & $10.1 \pm 0.07$ * & $8.6 \pm 0.05^{*}$ \\
\hline 12.5 & $9.8 \pm 0.13^{*}$ & $8.5 \pm 0.05^{*}$ \\
\hline 6.25 & $9.6 \pm 0.23 *$ & $8.5 \pm 0.13^{*}$ \\
\hline \multicolumn{3}{|l|}{ TS03 $(\mu \mathrm{g} / \mathrm{mL})$} \\
\hline 25 & $9.3 \pm 0.2$ & $8.2 \pm 0.66^{*}$ \\
\hline 12.5 & $8.6 \pm 0.05$ & $8.6 \pm 0.25^{*}$ \\
\hline 6.25 & $8.9 \pm 0.7$ & $8.9 \pm 0.1$ \\
\hline \multicolumn{3}{|l|}{ TS04 $(\mu \mathrm{g} / \mathrm{mL})$} \\
\hline 25 & $9.5 \pm 0.13$ & $8.9 \pm 0.00$ \\
\hline 12.5 & $9.1 \pm 0.13$ & $8.9 \pm 0.05$ \\
\hline 6.25 & $9.1 \pm 0.8$ & $9.1 \pm 0.16$ \\
\hline \multicolumn{3}{|l|}{ TS05 $(\mu \mathrm{g} / \mathrm{mL})$} \\
\hline 25 & $11.9 \pm 0.3^{*}$ & $12.3 \pm 2.3$ \\
\hline 12.5 & $10.5 \pm 0.76$ * & $11.8 \pm 0.2$ \\
\hline 6.25 & $10.9 \pm 0.03 *$ & $10.6 \pm 0.00$ \\
\hline \multicolumn{3}{|l|}{ TS06 $(\mu \mathrm{g} / \mathrm{mL})$} \\
\hline 25 & $11.4 \pm 0.17^{*}$ & $11.7 \pm 0.3$ \\
\hline 12.5 & $10.5 \pm 0.23 *$ & $10.5 \pm 0.16$ \\
\hline 6.25 & $9.8 \pm 0.16$ & $9.6 \pm 0.55$ \\
\hline \multicolumn{3}{|l|}{ TS07 $(\mu \mathrm{g} / \mathrm{mL})$} \\
\hline 25 & $9.6 \pm 0.3$ & $9.0 \pm 2.07$ \\
\hline 12.5 & $10.2 \pm 0.21 *$ & $9.0 \pm 0.5$ \\
\hline 6.25 & $10.3 \pm 0.02 *$ & $9.7 \pm 0.1$ \\
\hline
\end{tabular}

Note: $\left({ }^{*}\right)$ represents statistically significant values. Was used ANOVA and Dunnett's test.

of this mediator, and the most significant results were observed after incubation for $24 \mathrm{~h}$. In $48 \mathrm{~h}$, only TS02 produced significant amounts of NO in all concentrations tested, compared to untreated control (Table 2).

\subsection{Cell death analysis}

Parasites incubated with TS02 $\left(\mathrm{IC}_{50}\right.$ value) for $24 \mathrm{~h}$ have significantly labelling compatible with necrosis and apoptosis. Similar labelling was observed with AmB treatment (Fig. 5), however TS02 caused twice more labelling compatible with necrosis than AmB. On the other hand, TS01, TS03, TS04, TS05, TS06 and TS07 did not cause any significant changes in parasites, under experimental conditions applied (Data not shown).

\section{Discussion}

Cutaneous leishmaniasis is usually a debilitating disease, have no vaccine available, and chemotherapy, based on pentavalent antimonials, causes serious side effects with resistance to treatment related (WHO, 2015). Within this scenario, the search for new chemotherapeutic agents remains necessary. Medicinal chemistry has greatly contributed to generate structural changes in molecules to obtain new derivatives and has been a successful approach for new drugs design, based on known molecular targets in parasite (Monzote, 2009).

Thiosemicarbazones stand out for their broad pharmacological profile, whose properties have been widely studied due to possibility of handling their radicals, coordinating their mechanism of action. Among promising biological activities of these compounds can be highlight: anticonvulsant, antimicrobial, antiviral, antiparasitic and antitumor activities (Beraldo, 2004; Heng et al., 2015; Lessa et al., 2011a, 2011b; Santiago et al., 2014). Novel thiosemicarbazone synthesis was stimulated by its known inhibition activity on Trypanosoma cruzi and Leishmania sp. cysteine protease (Britta et al., 2012; Schroder et al., 2013).

In this work, we analyzed cytotoxicity compounds on mouse macrophages, since one of the main criteria in development of new compounds with leishmanicidal activity is low toxicity to mammalian cells and activity against parasite in low amounts (Liñares et al., 2006). Compounds demonstrated low toxicity on macrophages, and $\mathrm{CC}_{50}$ values were always lower than $\mathrm{IC}_{50}$ to promastigotas and amastigotes. The low toxicity of compounds towards macrophages had a direct effect on selectivity index values (SI), which were always more selective for parasites than to host cells.

Given that promastigote is parasite form present in insect vector, compounds activity in this form served as a starting point to determine leishmanicidal activity. $\mathrm{IC}_{50}$ values obtained for amastigotes were higher than promastigotes. However, it must be taken into consideration that action on amastigote form is complicated by the need for permeation across macrophage and parasitophorous

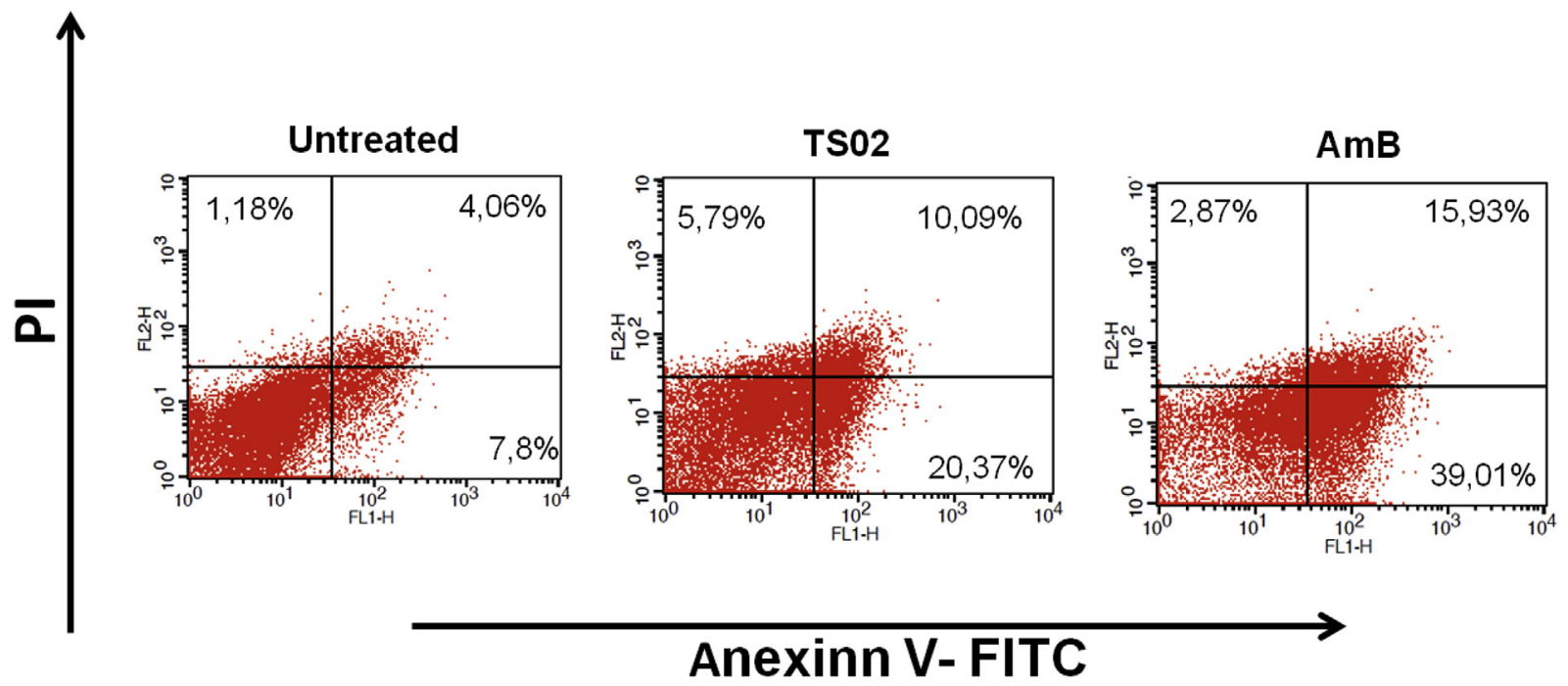

Fig. 5. Mechanisms of cell death induced by compound TS02. Note: TS02 and AmB were statistically significant. Was used ANOVA and Dunnett's test. 
vacuoles membranes before reaching parasite (Muylder et al., 2011).

Variations on leishmanicidal activity observed suggest that there is a structure-activity relationship for synthetic compounds tested, due to the variation in substituents added on scaffold molecule. On promastigotes, we observed that presence of ether (TS03) and dichloro (TS07) reduced $\mathrm{IC}_{50}$ values, while compounds with substitution by fluorine (TS04) and phenyl (TS02), have proved less effective against parasites.

To study the structure-antiparasitic activity relationships, we examined mono-substituents attached at 4-position of phenyl ring $(\mathrm{CH} 3, \mathrm{OCH} 3, \mathrm{~F}, \mathrm{Cl}, \mathrm{Br})$ in addition to a di-substituent (3,4-diCl). These substituents presented different electronic contribution to the phenyl group, allowing us to investigate the nature of each substituent for antiparasitic activity. In fact, the most selective compounds for promastigotes and amastigotes were TS03 and TS04, respectively. In common, both compounds carry out small substituents and $\mathrm{H}$-bond acceptors. The presence of a halogen in TSO4 possibly collaborated with this increased activity, as the use of halogen substituents contributes to halogen bond formation in pharmacological target, contributing to stability of drug-receptor binding (Zaldini et al., 2010). By comparing unsubstituted compound TS01 and methyl compound TS02, it is observed that increasing lipophilicity decreases antiparasitic activity. Other compounds such as TS05, TS06 and TS07 also have halogens in their structure and had low $\mathrm{IC}_{50}$ values in comparison to unsubstituted thiosemicarbazone TS01.

Macrophages have importance on process of susceptibility or resistance to leishmaniasis, once parasites multiply inside them. A primary resistance mechanism to Leishmania infection is nitric oxide production by infected macrophages. Important cytokines, as IFN- $\gamma$ and TNF, are produced on Th1 response and guide the induction of inducible nitric oxide synthase (iNOS), leading to NO production from L-arginine (Holzmuller et al., 2002; Küickelhaus et al., 2013; Lima-Junior et al., 2013).

Stimulated macrophages showed increased on NO production in the presence of all compounds (except TS04) at any moment, after stimulation for 24 or $48 \mathrm{~h}$. NO importance on parasite and course of leishmaniasis is known: parasite resistance to NO are correlated with larger lesions and absence of induction of TNF production, an important cytokine of Th1 profile, associated to leishmaniasis infection resistance (Giudice et al., 2007; Souza et al., 2010).

As cytokine production is closely related to patient's response to disease and treatment, in this work we analyze the influence of compounds on production of some cytokines important for leishmaniasis course, and which can be produced by macrophages: TNF, IL-12 and IL-10. In addition, thiosemicarbazones are known to regulate production of pro-inflammatory cytokines (as TNF and IL12) and anti-inflammatory cytokines (as IL-10) (Freitas et al., 2012). Compounds TS01, TS02, TS03, TS04, TS05 and TS06 were able to induce the production of pro-inflammatory cytokines. On the other hand, the production of IL-10 (anti-inflammatory cytokine) varied after thiosemicarbazones stimulation.

Although IL-10 stimulation is detrimental for facilitating parasite replication in host cells, pro-inflammatory cytokines such as IFN- $\gamma$, TNF and IL-12 may be toxic when produced in high amounts. IL-10 will block the Th1 cells activation, which can prevent the overproduction of these cytokines, avoiding tissue damage (Ribeiro-de-Jesus et al., 1998). Despite the importance of the Th1 on the cure of infection, it is worth emphasizing that the same cytokines involved in infection control may be related to the pathogenesis of disease. A balance is required with Th2-type cytokine producing cells: a Th1 x Th2 dichotomy (Reis et al., 2006).

Cell death mechanisms were evaluated on promastigotas and TS02, similar to AmB, was able to induct apoptosis and necrosis on parasites. Apoptosis, a process that can eliminate cells without causing an immune response is important in leishmaniasis pathogenesis context, is a process that can facilitate parasite survival inside macrophage (El-Hani et al., 2012) and it has been reported occurrence during the use of several reference drugs as antimonial, Miltefosine and AmB. On the other hand, necrotic process results in inflammation, consequence of action and activation of phagocytic cells, there recruitment of inflammatory cells associated with Th1 cytokines production which would result in disease remission. However with necrosis and increased pro-inflammatory cytokines in these lesions, there would also be the accumulation of neutrophils, which are related to increased levels of amastigotes and greater amount of drug to be healing of the lesions (Passero et al., 2010).

In conclusion, results demonstrated activity of thiosemicarbazone against $L$. amazonensis promastigotes and amastigotes, with low toxicity to peritoneal macrophages in vitro. Compounds tested also showed immunomodulation activity that may be relevant in leishmaniasis treatment and progression. Cell death induction was a significant found since it plays a central role in disease progression. Results obtained in this study confirmed important antiparasitic activity of thiosemicarbazones.

\section{Conflicts of interest}

The authors hereby declare that they have no conflicts of interest.

\section{Acknowledgments}

We are thankful to FACEPE, CNPq for financial support and FIOCRUZ for the use of its facilities.

\section{References}

Beraldo, H., 2004. Semicarbazonas e tiossemicarbazonas: o amplo perfil farmacológico e usos clínicos. Quim. Nov. 27, 461-471.

Boer, M. Den, Argaw, D., Jannin, J., Alvar, J., 2011. Leishmaniasis Impact and Treatment Access. October.

Britta, E.A., Silva, A.P.B., Ueda-Nakamura, T., Dias-Filho, B.P., Silva, C.C., Sernaglia, R.L., Nakamura, C.V., 2012. Benzaldehyde thiosemicarbazone derived from limonene complexed with copper induced mitochondrial dysfunction in Leishmania amazonensis. PLoS One 7, e41440. http://dx.doi.org/10.1371/ journal.pone.0041440.

Croft, S.L., Seifert, K., Yardley, V., 2006. Current scenario of drug development for leishmaniasis. Indian J. Med. Res. 399-410.

de Mello, T.F.P., Bitencourt, H.R., Pedroso, R.B., Aristides, S.M. a, Lonardoni, M.V.C Silveira, T.G.V., 2014. Leishmanicidal activity of synthetic chalcones in Leishmania (Viannia) braziliensis. Exp. Parasitol. 136, 27-34. http://dx.doi.org/ 10.1016/j.exppara.2013.11.003.

de Vries, H.J.C., Reedijk, S.H., Schallig, H.D.F.H., 2015. Cutaneous leishmaniasis: recent developments in diagnosis and management. Am. J. Clin. Dermatol 16, 99-109. http://dx.doi.org/10.1007/s40257-015-0114-Z.

El-Hani, C.N., Borges, V.M., Wanderley, J.L.M., Barcinski, M. a, 2012. Apoptosis and apoptotic mimicry in Leishmania: an evolutionary perspective. Front. Cell. Infect. Microbiol. 2, 96. http://dx.doi.org/10.3389/fcimb.2012.00096.

Freitas, M.L., De, Dalmolin, L., Oliveira, L.P., Moreira, R., Roman, S.S., Alexandre, F. Soares, A., Bresolin, L., Maria, M., Frescura, M., Brandão, R., 2012. Effects of Butane-2, 3-dione Thiosemicarbazone Oxime on Testicular Damage Induced by Cadmium in Mice, vol. 37, pp. 899-910.

Giudice, A., Camada, I., Leopoldo, P.T.G., Pereira, J.M.B., Riley, L.W., Wilson, M.E. Ho, J.L., Jesus, A.R., De, Carvalho, E.M., Almeida, R.P., 2007. Resistance of Leishmania (Leishmania) Amazonensis and Leishmania (Viannia) Braziliensis to Nitric Oxide Correlates with Disease Severity in Tegumentary Leishmaniasis, vol. 12, pp. 1-12. http://dx.doi.org/10.1186/1471-2334-7-7.

Gurung, P., Kanneganti, T.-D., 2015. Innate immunity against Leishmania infections. Cell. Microbiol. n/a-n/a. http://dx.doi.org/10.1111/cmi.12484.

Heng, M.P., Sinniah, S.K., Teoh, W.Y., Sim, K.S., Ng, S.W., Cheah, Y.K., Tan, K.W., 2015 Synthesis of a DNA-targeting nickel (II) complex with testosterone thiosemicarbazone which exhibits selective cytotoxicity towards human prostate cancer cells (LNCaP). Spectrochim. Acta Part A Mol. Biomol. Spectrosc. 150, 360-372. http://dx.doi.org/10.1016/j.saa.2015.05.095.

Holzmuller, P., Sereno, D., Cavaleyra, M., Mangot, I., Daulouede, S., Vincendeau, P., Lemesre, J., 2002. Nitric Oxide-mediated DNA Fragmentation in Leishmania 
Amazonensis Amastigotes Nitric Oxide-mediated Proteasome-dependent Oligonucleosomal DNA Fragmentation in Leishmania Amazonensis Amastigotes. http://dx.doi.org/10.1128/IAI.70.7.3727.

Kückelhaus, C.S., Kückelhaus, S. a S., Tosta, C.E., Muniz-Junqueira, M.I., 2013. Pravastatin modulates macrophage functions of Leishmania (L.) amazonensisinfected BALB/c mice. Exp. Parasitol. 134, 18-25. http://dx.doi.org/10.1016/ j.exppara.2013.01.020.

Leite, A.C.L., Barbosa, F.F., Cardoso, M.V.D.O., Moreira, D.R.M., Coelho, L.C.D., da Silva, E.B., Filho, G.B.D.O., de Souza, V.M.O., Pereira, V.R. a, de C. Reis, L., Ferreira, P.M.P., Pessoa, C., Wanderley, A.G., Mota, F.V.B., da Silva, T.G., 2013. Phthaloyl amino acids as anti-inflammatory and immunomodulatory prototypes. Med. Chem. Res 1-8. http://dx.doi.org/10.1007/s00044-013-0730-1.

Leprohon, P., Fernandez-Prada, C., Gazanion, É., Monte-Neto, R., Ouellette, M., 2015. Drug resistance analysis by next generation sequencing in Leishmania. Int. J. Parasitol. Drugs Drug Resist 5, 26-35. http://dx.doi.org/10.1016 j.ijpddr.2014.09.005.

Lessa, J.A., Guerra, J.C., de Miranda, L.F., Romeiro, C.F.D., Da Silva, J.G., Mendes, I.C. Speziali, N.L., Souza-Fagundes, E.M., Beraldo, H., 2011a. Gold(I) complexes with thiosemicarbazones: cytotoxicity against human tumor cell lines and inhibition of thioredoxin reductase activity. J. Inorg. Biochem. 105, 1729-1739. http:/ dx.doi.org/10.1016/j.jinorgbio.2011.09.008.

Lessa, J.A., Reis, D.C., Mendes, I.C., Speziali, N.L., Rocha, L.F., Pereira, V.R. a Melo, C.M.L., Beraldo, H., 2011b. Antimony(III) complexes with pyridine-derived thiosemicarbazones: structural studies and investigation on the antitrypanosomal activity. Polyhedron 30, 372-380. http://dx.doi.org/10.1016/ j.poly.2010.11.004.

Lima-Junior, D.S., Costa, D.L., Carregaro, V., Cunha, L.D., Silva, A.L., Mineo, T.W. Gutierrez, F.R., Bellio, M., Bortoluci, K.R., Flavell, R.A., Bozza, M.T., Silva, J.S., Zamboni, D.S., 2013. Inflammasome-derived IL-1ß Production Induces Nitric Oxide-mediated Resistance to Leishmania.Pdf.

Liñares, G.E.G., Ravaschino, E.L., Rodriguez, J.B., 2006. Progresses in the field of drug design to combat tropical protozoan parasitic diseases. Curr. Med. Chem. 13 $335-360$.

Magalhaes Moreira, D.R., De Oliveira, A.D.T., Teixeira De Moraes Gomes, P.A, De Simone, C.A., Villela, F.S., Ferreira, R.S., Da Silva, A.C., Dos Santos, T.A.R., Brelaz De Castro, M.C.A., Pereira, V.R.A., Leite, A.C.L., 2014. Conformational restriction of aryl thiosemicarbazones produces potent and selective anti-Trypanosoma cruzi compounds which induce apoptotic parasite death. Eur. J. Med. Chem. 75, 467-478. http://dx.doi.org/10.1016/j.ejmech.2014.02.001.

Monzote, L., 2009. Current Treatment of Leishmaniasis: a Review, pp. 9-19.

Mottram, J.C., Coombs, G.H., Alexander, J., 2004. Cysteine peptidases as virulence factors of Leishmania. Curr. Opin. Microbiol. 375-381. http://dx.doi.org/10.1016/ j.mib.2004.06.010.
Muylder, G., De, Ang, K.K.H., Chen, S., Arkin, M.R., Engel, J.C.,H.,J., 2011. A screen against Leishmania intracellular Amastigotes: comparison to a promastigote screen and identification of a host cell-specific hit. Screening 5. http:// dx.doi.org/10.1371/journal.pntd.0001253.

Passero, L.F.D., Marques, C., Vale-Gato, I., Corbett, C.E.P., Laurenti, M.D., SantosGomes, G., 2010. Histopathology, humoral and cellular immune response in the murine model of Leishmania (Viannia) shawi. Parasitol. Int. 59, 159-165. http:// dx.doi.org/10.1016/j.parint.2009.12.010.

Reis, LD.C, Felinto De Brito, M.E. Souza, M.D.A. Pereira, V.R.A. 2006. Mecanismos imunológicos na resposta celular e humoral na leishmaniose tegumentar americana, 35, 103-115.

Ribeiro-de-Jesus, A., Almeida, R.P., Lessa, H., Bacellar, O., Carvalho, E.M., 1998. Cytokine profile and pathology in human leishmaniasis. Braz. J. Med. Biol. Res. 31, 143-148.

Santiago, E.D.F., Oliveira, A., De, Oliveira, B., De, Magalhaes, R., 2014. Eval. AntiSchistosoma mansoni Activity Thiosemicarbazones Thiazoles 58, 352-363. http://dx.doi.org/10.1128/AAC.01900-13.

Schad, C., Baum, U., Frank, B., Dietzel, U., Mattern, F., Gomes, C., Ponte-sucre, A., Moll, H., 2016. Development of a New Antileishmanial Aziridine-2, 3-Dicarboxylate- based Inhibitor with High Selectivity for Parasite Cysteine Proteases, 60, pp. 797-805. http://dx.doi.org/10.1128/AAC.00426-15.Address.

Schroder, J., Noack, S., Marhofer, R.J., Mottram, J.C., Coombs, G.H., Selzer, P.M., 2013. Identification of semicarbazones, thiosemicarbazones and triazine nitriles as inhibitors of Leishmania mexicana cysteine protease CPB. PLoS One 8, 1-12. http://dx.doi.org/10.1371/journal.pone.0077460.

Soflaei, S., Dalimi, A., Ghaffarifar, F., Shakibaie, M., Shahverdi, A.R., Shafiepour, M. 2012. In Vitro antiparasitic and apoptotic effects of antimony sulfide nanoparticles on Leishmania infantum. J. Parasitol. Res. 756568. http://dx.doi.org/ 10.1155/2012/756568.

Souza, A.S., Giudice, A., Pereira, J.M.B., Guimarães, L.H., de Jesus, A.R., de Moura, T.R. Wilson, M.E., Carvalho, E.M., Almeida, R.P., 2010. Resistance of Leishmania ( Viannia ) braziliensis to nitric oxide: correlation with antimony therapy and TNF- $\alpha$ production. BMC Infect. Dis. 10, 209. http://dx.doi.org/10.1186/14712334-10-209.

WHO, 2010. Report of a Meeting of the WHO Expert Committee on the 22-26.

WHO, 2015. Leishmaniasis Fact Sheet.

Zaldini, M., Montenegro, M., Cristina, A., Leite, L., Veríssimo, M., Cardoso, O. Rodrigo, D., Moreira, M., José, D., Alberto, C., Campos, L., Assis, M., Rego, V., Pereira, A., Salgado, R., Hobson, J., 2010. Bioorganic \& Medicinal Chemistry Studies toward the structural optimization of novel thiazolylhydrazone-based potent antitrypanosomal agents. Bioorg. Med. Chem. 18, 7826-7835. http:// dx.doi.org/10.1016/j.bmc.2010.09.056. 